\title{
Severe ischemic mitral regurgitation: Repair or replace?
}

\author{
Michael A. Acker, MD, ${ }^{\mathrm{a}}$ François Dagenais, MD, ${ }^{\mathrm{b}}$ Daniel Goldstein, MD, ${ }^{\mathrm{c}}$ Irving L. Kron, MD, ${ }^{\mathrm{d}}$ and \\ Louis P. Perrault, $\mathrm{MD}, \mathrm{PhD}^{\mathrm{e}}$
}

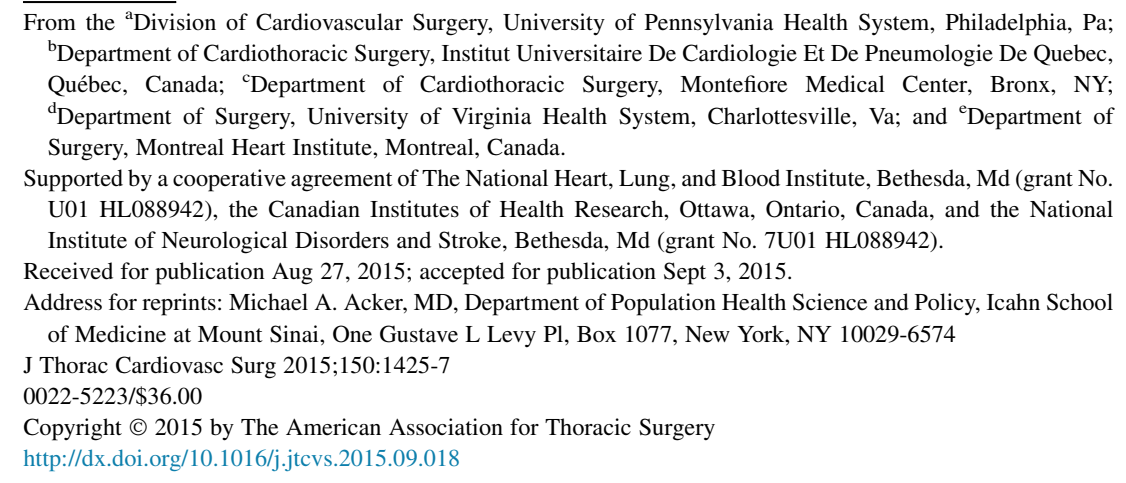

Both European and US guidelines for the management of patients with valvular heart disease stipulate that mitral valve surgery can be considered for patients with severe functional (secondary) mitral regurgitation (MR) who remain significantly symptomatic despite optimal medical therapy, including cardiac resynchronization when indicated. ${ }^{1,2}$ This relatively weak, class IIb recommendation is predicated on the uncertainty as to the degree to which the benefit of surgical intervention outweighs the risks inherent in surgery for these patients with challenging pathology, and does not specify the type of surgical intervention to be performed. The choice between mitral valve (MV) repair and replacement for severe, functional MR must weigh the lower short- and intermediate-term morbidity and mortality associated with repair against the more predictable eradication of MR with replacement. ${ }^{3-6}$ Until recently, this choice was informed mostly by retrospective and single-center observational studies that included relatively few patients undergoing chordalsparing MV replacement, a technique now known to be important for the preservation of left ventricle (LV) geometry and function.

The evidence base to support surgical decision making for chordal-sparing MV replacement versus repair for the operative treatment of severe ischemic MR includes a large, retrospective, propensity-matched study of 1006 patients (244 matched pairs) with LV dysfunction (ejection fraction < 0.40) cared for at 13 Italian institutions over a 15-year time frame (1996-2011). ${ }^{7}$ The median qualitative MR grade as assessed by echocardiography for the matched pairs was $2.8 \pm 0.5$ on a scale of 0 to 4 . There was no difference in short- or long-term mortality rates between matched pairs treated with MV replacement or repair. Furthermore, no between-group differences in long-term LV function, cardiac- or valve-related mortality, or exercise capacity were identified. MV repair was the strongest $P<.001)$.

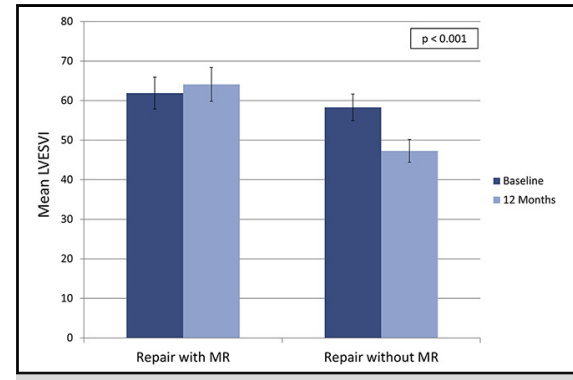

Patients undergoing repair without recurrent mitral regurgitation have lower left ventricular end-systolic volume index than those patients with recurrent mitral regurgitation $(P<.001)$

\section{Central Message}

Optimal choice between MV repair or replacement for severe functional MR should depend on tethering and remodeling characteristics.

\section{Perspective}

A recent randomized trial did not find any clinical differences between MV repair or MV replacement for severe functional MR at 1 year. The authors drew on a variety of sources of evidence about leaflet tethering and adverse LV remodeling to provide insight into the optimal choice between surgical options for individual patients.

See Letter page 1666.

multivariable predictor of the need for valve-related reoperation (hazard ratio, 2.9; 95\% confidence interval, 2.5-3.2;

A recently reported National Institutes of Health and Canadian Institute of Health Research-sponsored Cardiothoracic Surgical Trials Network (CTSN) randomized trial ${ }^{8}$ in 251 patients with severe ischemic MR (defined using an integrative echocardiographic method) demonstrated no difference at 1 year in the primary end point of reverse LV remodeling (change from baseline in LV end-systolic volume index) between patients undergoing MV replacement and repair. In addition, no difference was found between groups with respect to 30-day or 1-year mortality, major adverse cardiac and cerebrovascular events, or quality of life. In this randomized trial, the rates of recurrent moderate or severe MR in surviving patients at 1 and 2 years after repair was $32.6 \%$ and $46 \%$, respectively. ${ }^{9}$ Moderate 


\section{Abbreviations and Acronyms \\ MR = mitral regurgitation \\ $\mathrm{MV}=$ mitral valve \\ $\mathrm{LV}=$ left ventricle \\ CTSN $=$ Cardiothoracic Surgical Trials Network}

recurrent MR, which constituted the vast majority of this combined end point, did not generally progress to severe MR over 2 years of follow-up. In a nonprespecified subgroup analysis, patients undergoing MV repair who did not develop recurrent MR showed significantly greater reductions in LV end-systolic volume index (ie, reverse remodeling) than patients with recurrent MR.

Several observational studies have identified predictors of recurrent ischemic MR after MV repair. These factors fall into 2 categories: echocardiographic parameters of the extent of MV leaflet tethering and indices of adverse LV remodeling/dilation. The former include anterior and posterior leaflet angles, leaflet tethering length, and leaflet tenting area. Investigators have also identified the angle between the tip of the anterior leaflet and the annular plane as a strong predictor of MR recurrence. An anterior leaflet angle $>25^{\circ}$ to $39.5^{\circ 10-14}$ has been independently associated with recurrent MR and may be of relatively greater importance than other echocardiographic measures of leaflet tethering (eg, posterior leaflet angle, coaptation depth, and tenting area) or indices of LV size or sphericity. LV size and function and the qualitative degree of MR have also been identified as key independent determinants of recurrent MR. ${ }^{15-23}$ In the CTSN trial, the strongest (and only independent) predictor of recurrent MR in the repair group was the presence of basal aneurysm/dyskinesis. This was 1 of 10 preoperative factors that served as the basis for a predictive model for patients at highest risk of recurrent MR (area under the receiver operating characteristics curve, 0.82). Surprisingly, preoperative echocardiographic measures of MV tethering were not independently predictive of MR recurrence.

Based on these observations, we believe that the presence of basal aneurysm/dyskinesis, echocardiographic evidence of significant leaflet tethering, and/or moderate to severe LV dilation favor the use of chordal-sparing mitral valve replacement over mitral valve repair for treatment of medically refractory severe ischemic MR. In the absence of basal aneurysm/dyskinesis, the echocardiographic evidence of significant leaflet tethering, or moderate to severe LV dilation, MV repair using an undersized, complete, rigid ring may be reasonable. More complex mitral repair operations that specifically address leaflet tethering have shown promising results, ${ }^{24-27}$ but remain investigational and incompletely validated.
Long-term follow-up of the surviving patients in this CTSN trial will be important to better understand the clinical consequences of moderate/severe recurrent MR in the repair group, the incidence of prosthesis-related complications, heart failure hospitalizations, quality of life, and survival.

\section{Conflict of Interest Statement}

Dr Goldstein is on the medical advisory board and is a surgical proctor for Heartware, Inc; acts as a consultant for Medtronic, Inc; and also holds the Data and Safety Monitoring Board chair for the C-Pulse System: A Heart Assist Device Clinical Study (COUNTER HF) trail, Sunshine Heart, Inc. All other authors have nothing to disclose with regard to commercial support.

\section{References}

1. Vahanian A, Alfieri O, Andreotti F, Antunes MJ, Barón-Esquivias G, Baumgartner H, et al. Guidelines on the management of valvular heart disease (version 2012). Eur Heart J. 2012;33:2451-96.

2. Nishimura RA, Otto CM, Bonow RO, Carabello BA, Erwin JP III, Guyton RA, et al. 2014 AHA/ACC guideline for the management of patients with valvular heart disease: a report of the American College of Cardiology/American Heart Association Task Force on Practice Guidelines. J Am Coll Cardiol. 2014;63: e57-185.

3. Vassileva CM, Boley T, Markwell S, Hazelrigg S. Meta-analysis of short-term and long-term survival following repair versus replacement for ischemic mitral regurgitation. Eur J Cardiothoracic Surg. 2011;39:295-303.

4. Di Salvo TG, Acker MA, Dec GW, Byrne JG. Mitral valve surgery in advanced heart failure. J Am Coll Cardiol. 2010;5:271-82.

5. Grossi EA, Goldberg JD, LaPietra A, Ye X, Zakow P, Sussman M, et al. Ischemic mitral valve reconstruction and replacement: comparison of long-term survival and complications. J Thorac Cardiovasc Surg. 2001;122:1107-24.

6. Gillinov AM, Wierup PN, Blackstone EH, Bishay ES, Cosgrove DM, White J, et al. Is repair preferable to replacement for ischemic mitral regurgitation? J Thorac Cardiovasc Surg. 2001;122:1125-41.

7. Lorusso R, Gelsomino S, Vizzardi E, D’Aloia A, De Cicco G, Lucà F, et al. Mitral valve repair or replacement for ischemic mitral regurgitation? The Italian Study on the Treatment of Ischemic Mitral Regurgitation (ISTIMIR). J Thorac Cardiovasc Surg. 2013;145:128-39.

8. Acker MA, Parides MK, Perrault LP, Moskowitz AJ, Gelijns AC, Voisine P, et al. Mitral valve repair versus replacement for severe ischemic mitral regurgitation. N Engl J Med. 2014;370:23-32.

9. Kron IL, Hung J, Overbey JR, Bouchard D, Gelijns AC, Moskowitz AJ, et al. Predicting recurrent mitral regurgitation after mitral valve repair for severe ischemic mitral regurgitation. J Thorac Cardiovasc Surg. 2015;149:752-61.

10. Magne J, Pibarot P, Dumesnil JG. Sénéchal. Continued global left ventricular remodeling is not the sole mechanism responsible for the late recurrence of ischemic mitral regurgitation after restrictive annuloplasty. J Am Soc Echocardiogr. 2009;22:1256-64.

11. Lee AP, Acker M, Kubo SH, Bolling SF, Park SW, Bruce CJ, et al. Mechanisms of recurrent functional mitral regurgitation after mitral valve repair in non-ischemic dilated cardiomyopathy: importance of distal anterior leaflet tethering. Circulation. 2009;119:2606-14.

12. Gelsomino S, Lorusso R, DeCicco G, Capecchi I, Rostagno C, Caciolli S, et al. Five-year echocardiographic results of combined undersized mitral ring annuloplasty and coronary artery bypass grafting for chronic ischaemic mitral regurgitation. Eur Heart J. 2008;29:231-40.

13. Onarati F, Rubino A, Marturano D, Pasceri E, Santarpino G, Zinzi S, et al. Midterm clinical and echocardiographic results and predictors of mitral regurgitation on recurrence following restrictive annuloplasty for ischemic cardiomyopathy. J Thorac Cardiovasc Surg. 2009; 138:654-62.

14. Haan CK, Cabral CI, Conetta DA, Coombs LP, Edwards FH. Selecting patients with mitral regurgitation and left ventricular dysfunction for isolated mitral valve surgery. Ann Thorac Surg. 2004;78:820-5. 
15. Shiota M, Gillinov AM, Takasaki K, Fukuda S, Shiota T. Recurrent mitral regurgitation late after annuloplasty for ischemic mitral regurgitation. Echocardiography. 2011;28:161-6.

16. Crabtree TD, Bailey MS, Moon MR, Munfakh N, Pasque MK, Lawton JS, et al. Recurrent mitral regurgitation and risk factors for early and late mortality after mitral valve repair for functional ischemic mitral regurgitation. Ann Thorac Surg. 2008;85:1537-43.

17. Gelsomino S, van Garasse L, Lucà F, Lorusso R, Cheriex E, Rao CM, et al. Impart of preoperative anterior leaflet tethering on the recurrence of ischemic mitral regurgitation and the lack of left ventricular reverse remodeling after restrictive annuloplasty. J Am Soc Echocardiogr. 2011;24:1365-75.

18. Jeno T, Sakata R, Iguro Y, Yamamoto H, Ueno T, Matsumoto K. Preoperative advanced left ventricular remodeling predisposes to recurrence of ischemic mitral regurgitation with less reverse remodeling. J Heart Valve Dis. 2008;17:36-41.

19. DeBonis M, Lapenna E, Verzini A, LaCanna G, Grimaldi A, Torracca L, et al. Recurrence of mitral regurgitation parallels the absence of left ventricular reverse remodeling after mitral valve repair in advanced dilated cardiomyopathy. Ann Thorac Surg. 2008;85:932-9.

20. Lee LS, Kwon MH, Cevasco M, Schmitto JD, Mokashi SA, McGurk S, et al. Postoperative recurrence of mitral regurgitation after annuloplasty for functional mitral regurgitation. Ann Thorac Surg. 2012;94:1211-7.

21. Bax JJ, Braun J, Somer ST, Klautz R, Holman ER, Versteegh MI, et al. Restrictive annuloplasty and coronary revascularization in ischemic mitral regurgitation results in reverse left ventricular remodeling. Circulation. 2004;110:II103-8.
22. DiGiammarco G, Liberi R, Giancane M, Canosa C, Gallina S, DiFrancesco A et al. Recurrence of functional mitral regurgitation in patients with dilated cardiomyopathy undergoing mitral valve repair: how to predict it. Interact Cardiovasc Thorac Surg. 2007;6:340-4.

23. Ciarka A, Braun J, Delgado V, Versteegh M, Boersma K, Klaurtz R, et al. Predictors of mitral regurgitation recurrence in patients with heart failure undergoing mitral valve annuloplasty. Am J Cardiol. 2010;106:395-401.

24. Szymanski C, Bel A, Cohen I, Touchot V, Handschumacher MD, Desnos M, et al Comprehensive annular and subvalvular repair of chronic ischemic mitral regurgitation improves long-term results with the least ventricular remodeling. $\mathrm{Circu}$ lation. 2012;126:2720-7.

25. Bouma W, van der Horst ICC, Wijdh-den-Hamer IJ, Erasmus ME, Zijlstra F, Mariani MA, et al. Chronic ischemic mitral regurgitation. Current treatment results and new mechanism-based surgical approaches. Eur J Cardiothorac Surg. 2010;37:170-85.

26. Borger MA, Murphy PM, Alam A, Fazel S, Maganti M, Armstrong S, et al. Initial results of the chordal-cutting operation for ischemic mitral regurgitation. I Thorac Cardiovasc Surg. 2007;133:1483-92.

27. Magne J, Senechal M, Dumesnil JG, Pibarot P. Ischemic mitral regurgitation: a complex multifaceted disease. Cardiology. 2009;112:244-59.

Key Words: mitral valve surgery, severe ischemic mitral valve regurgitation, clinical trial 